\title{
INTELLIGENT TUTORING SYSTEM FOR DISTANCE EDUCATION
}

\author{
Jose Dutra de Oliveira Neto \\ Elby Vaz Nascimento \\ Universidade de São Paulo, São Paulo, Brazil
}

\begin{abstract}
This study aims to develop and implement a tool called intelligent tutoring system in an online course to help a formative evaluation in order to improve student learning. According to Bloom et al. $(1971,117)$ formative evaluation is a systematic evaluation to improve the process of teaching and learning. The intelligent tutoring system may provide a timely and high quality feedback that not only informs the correctness of the solution to the problem, but also informs students about the accuracy of the response relative to their current knowledge about the solution. Constructive and supportive feedback should be given to students to reveal the right and wrong answers immediately after taking the test. Feedback about the right answers is a form to reinforce positive behaviors. Identifying possible errors and relating them to the instructional material may help student to strengthen the content under consideration. The remedial suggestion should be given in each answer with detaileddescription with regards the materials and instructional procedures before taking next step. The main idea is to inform students about what they have learned and what they still have to learn. The open-source LMS called Moodle ${ }^{\mathrm{TM}}$ was extended to accomplish the formative evaluation, high-quality feedback, and the communal knowledge presented here with a short online financial math course that is being offered at a large University in Brazil. The preliminary results shows that the intelligent tutoring system using high quality feedback helped students to improve their knowledge about the solution to the problems based on the errors of their past cohorts. The results and suggestion for future work are presented and discussed.
\end{abstract}

Keywords: Formative assessment, feedback, intelligent tutoring system..

Recebido em/Manuscript first received: 03/04/2010 Aprovado em/Manuscript accepted: 24/02/2012

Endereço para correspondência/ Address for correspondence

Jose Dutra de Oliveira Neto, Mestre em Engenharia Elétrica pela Universidade Estadual de Campinas (1987) e Doutor em Controladoria e Contabilidade pela Universidade de São Paulo (1999). Pós Doutorado na University of Illinois at Urbana-Champaign na faculdade de Educação sobre Qualidade em EaD. Professor Livre-docente pela Universidade de São Paulo, Brasil, E-mail: dutra@usp.br

Elby Vaz Nascimento, Bacharel em Análise de Sistema pelo Centro Universitário de Lins (UNILINS). Analista de sistema e desenvolvedor. Atua na área de TI no UNICEP - Centro Universitário Central Paulista. Mestrando na EESC-USP, Brasil. E-mail: elbyvaz@yahoo.com.br

ISSN online: 1807-1775

Publicado por/Published by: TECSI FEA USP - 2012 


\section{INTRODUCTION}

The traditional mode of education (formal education) is still the most common in Brazilian higher education institutions (HEIs). In this educational model, teachers play an active role and impart their knowledge to students, who receive information passively. In general, one of the features of traditional formal education is to follow a unidirectional teaching methodology, which prevents students from taking a more active and flexible part in their learning process (Dib, 1988).

Vasconcellos, Oliveira, \&Berbel (2006) regard the traditional mode of education as a practice constrained by classroom time and space. The academic directives of HEIs that employ traditional teaching modes usually include an assessment system linked to grades and pass-fail procedures. These procedures justify the existence of mid- and/or end-of-process assessment practices, which place too much weight on the grades.

Another teaching-learning mode - on which this study is based-is the nonformal education. It follows a bidirectional, non-contiguous methodology (teacher $\leftrightarrow$ student). This flexible methodology is capable of adapting to students' needs and interests (Dib, 1988).

As a support of this approach, Souza (2003) sustains that the teaching-learning process should be consistent with students' intellectual development, i.e., it should help teachers to identify and adapt their teaching practices to different cognitive levels of different students.

In order to meet students' specific needs it is necessary to measure their cognitive development throughout the course/program by means of an assessment process. According to Piletti (1987), assessment is an ongoing investigation process aimed at interpreting students' knowledge, skills, and attitudes in view of expected or desired behavioral changes. The existing types of assessment are: (a) diagnostic assessment, which seeks to identify students' competencies, and assign them to different groups or learning levels; (b) formative assessment, whose goal is to collect data during the teaching-learning process so as to guide it; and (c) summative assessment, which measures the results of a process, usually conducted at its end.

Based on the information gathered during the formative assessment, it is possible to affect students' learning process. This may be facilitated by intelligent tutors through timely and high-quality feedback.

As stated by Oliveira Neto, Cornachione Junior, \& Nascimento (2009), feedback is more effective when it provides information about students' progress and/or information that can help them to advance in their studies. The purpose of this information is to change their thinking/behavior and improve their learning/academic performance.

In the specific case of online courses in Financial Mathematics offered in Brazil, it may be observed that their assessment processes usually employ automated assessment tools such as multiple-choice tests. These tests notify students about their success or failure, but fail to inform them about the accuracy of their answers as regards their knowledge. For this reason, this type of automated system has limited use in more 
complex learning processes. In addition, it could benefit substantially from quality and timely feedback (Pisan et al., 2002).

Instructional design is a very important step for the planning and development of online courses with intelligent tutoring. Knowledge of the teaching model, instructional strategies, and instructional technologies are essential to successful online courses.

Given the aforementioned context, this study aims at assessing the use of intelligent tutoring in the form of intelligent feedback in a distance learning course in Financial Mathematics designed according to the instructional design model called ILDF called ILDF (Integrative Learning Design Framework) online supported by the communal-knowledge theory.

In order to achieve this objective, specific goals were defined as follows: (a) creation of some rules based on students' mistakes from previous offerings of the same course and feed them into a knowledge base; (b) design of an online course according to the instructional model adopted; (c) implementation of intelligent tutoring-based on this knowledge base by means of intelligent feedback - as part of formative assessment in the course; and (d) piloting of the course with a sample of students and evaluating its results.

\section{THEORETICAL UNDERPINNINGS}

According to Oliveira (1999), intelligence in intelligent teaching systems is based on students' knowledge deriving from the analysis of their interaction with the subject matter. Based on this analysis, an artificial intelligent agent identifies students' cognitive profiles and adapts them to the learning needs matching these profiles, i.e., pedagogical contents available to students are adjusted to their learning needs in order to optimize .

The studies related to the theme addressed in this investigation focus on three dimensions: formative assessment, feedback, and communal knowledge.

Formative assessment assists Intelligent Systems throughout a distance education (DE) course by means of intelligent tutoring, which may be supported by intelligent feedback. Based on students' experiences, a knowledge base developed in accordance with the communal knowledge theory was employed to inform intelligent tutoring (Figure 1).

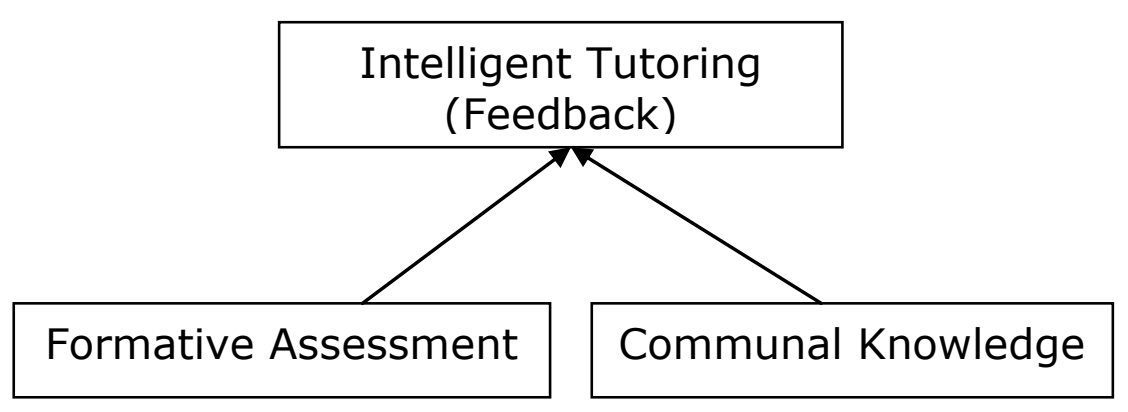

Figure 1 -Theoretical framework of the study. 
Formative assessment has been investigated as a way to evaluate and provide students with feedback during their learning process as opposed to summative assessment done at the end of the course.

As stated by Pirenos (1999), formative assessment may be seen as a type of continual assessment aimed at improving ongoing learning processes, thereby contributing to guidance and monitoring of students during their training period. Formative assessment is the kind of assessment that helps students learn and grow and is part of learning regulation and development in terms of an educational project. It is interesting to note that for the practice of formative assessment it is important to collect data generated by the students during the course, because only then the teacher can be aware of their real situation and prepare for a possible intervention.

As reported by Otsuka et al. (2002), continual assessment in online courses can be done by analyzing learners' records of participation in the course (activities, interactions, and collaboration among learners). This assessment mode is particularly relevant in $\mathrm{DE}$ as it allows teachers to observe students' behaviors, promotes the identification of problems, and enables the authentication of students' identities.

Along these lines, Rosa \& Maltempi (2006) indicate their search for online assessment methods that facilitate formative assessment of student performance. It is believed that student training will be acknowledged as the center of teaching and learning. Thus, it is up to the teacher to promote formative assessment so as to contribute to the cognitive process established through learning actions.

Maximo, Raabe, \& Barone (2007) point that for effective teaching and learning to occur, it is necessary to adopt a type of assessment that is more formative than summative.

The fact that teachers can intervene in student learning demonstrates that they do not only act as mere observers, but also as agents who challenge the research subjects, questioning their answers. One of the goals of this behavior is to observe how a person's intervention affects another's performance.

In essence, Rosa \& Maltempi (2006) claim that formative assessment emphasizes the process over the product; it is decoupled from the quantification of knowledge and linked to educating individuals.

Ferreira \& Carvalho (2004) use the term "formative assessment" to refer to all the activities conducted by teachers and students providing information that can be used as feedback to improve teaching and learning.

In short, the literature indicates that formative assessment holds great potential. This study indicates the possibility of implementing this type of assessment by means of intelligent feedback as an application of intelligent tutoring.

Feedback may be understood as regeneration and response, but according to Bulhava (1977), feedback can be defined as an action employed to inform learners whether their answers are right or wrong. In addition, it can also be employed to give new instructions instead of merely imparting the correct answer to students.

Wilges et al. (2007) advocate that teaching situations should be presented as small, increasingly complex teaching units and that at the end of each unit there should be questions and feedback rewarding students for their hits or assisting them when they 
make mistakes. It is possible to see the merit given to feedback in this kind of assessment. It is important to remark that these authors do not indicate feedback just as a way of assisting students when they are wrong, but also as a way of validating their knowledge when they are right.

The importance of feedback to facilitate teaching and learning has been widely acknowledged, especially because it can be employed as confirmation (i.e., confirmation of correct answers) and correction (i.e., indication of mistakes by teachers and their correction by students) (Birenbaum \& Tatsuoka, 1987).

Along these lines, Kulhavy (1977) argues that it is necessary to deal with the correct and incorrect answers independently. The purpose of feedback on a correct answer is to show learners that their understanding is appropriate to the lesson taught. A correct answer matches the feedback, i.e., students are able to realize that their understanding of the subject matter is correct. On the other hand, the feedback on a mistake is more important than providing confirmation of a correct answer, because when a mistake has been made, not only does feedback eliminate the wrong answer, but also replaces it with correct information. Once the error has been identified, students will seek to correct it and replace it with correct information, resorting to the theory in question and background materials.

In addition to being employed to assist students in their learning process, feedback can also be used in a different way. Klecker (2007) claims that feedback given as reinforcement works both as extrinsic motivation-when other students are involved-and as intrinsic motivation-when the student is motivated to selfcorrection.

In order to ascertain the importance of using feedback in learning, the results of two studies by different authors are briefly described: (a) Klecker (2007) conducted a survey with 77 students, who participated in online course assessments; students who were aided by formative feedback during tests scored higher than those who were not; (b) Gilman (1969) also conducted a study with 75 students divided into two groups, and with only one feedback was employed as reinforcement; after a week of lessons, training, and tests, the performance of the group that had had feedback as part of the learning process was significantly higher than that of the control group. The author affirms that not only does feedback work as reinforcement, but it also provides additional information, because students - regardless of getting it right or wrong - are redirected to supplementary materials, which are conducive to knowledge broadening.

In another study, Birenbaum\&Tatsuoka (1987) also concluded that students that had received feedback as guidance performed better and learned more effectively than those who had had none.

The lack of timely and high-quality feedback has been pointed as a critical factor in the teaching-learning process. Usually, two evaluations per semester are conducted on average in courses with large classes. As a result, students have limited opportunities to learn from their mistakes, since it is difficult for instructors to monitor student progress. The solution, according to Pisan et al. (2002), is to automate the process.

Feedback has a potential use in DE courses since it allows training to be more personalized. In large classes, common in DE, individual monitoring of each student is a very difficult task for the teacher, in view of the large amount of information generated in the virtual learning environment (VLE). 
Consequently, students are the ones to benefit the most from technology-aided feedback, because from the moment that teachers start working with students on an individual basis, the latter, in turn, become more motivated to do their tasks, express their question, and interact with their teachers and peers. In short, despite being of assistance to the teacher, technology may promote more student learning at the end of the course.

Bloom, Hastings, \&Madaus (1971) also suggest that a wrong statement be accompanied by a detailed compilation of teaching materials (textbooks, tutorials, URLs or movies) to be consulted by students in order to correct their mistakes and improve their knowledge about the subject matter in question. It is desirable that this statement be very specific, preferably indicating pages or chapters of books, sites, links, and so on.

Intelligent feedback should be provided by a knowledge base originated from students' teaching and learning experiences. The communal knowledge theory was employed to create this knowledge base.

Communal knowledge is a term employed to represent the possibility provided by DE to students of creating and contributing to the storage of new knowledge in any form (e.g., projects, artifacts, and experiences) in a shared knowledge base for the benefit of other students new to the learning community (Holmes \& Gardner, 2006).

According to Holmes \& Gardner (2006), communal knowledge comes into being when students create their own knowledge as a result of experiences and interactions. Students are also responsible for feeding their knowledge into a shared knowledge base so as to help newcomers to the community.

Holmes et al. (2008) claim that communal knowledge is rooted in the assumption that students and teachers will not engage just in developing their own information but that they will also actively engage in creating knowledge to benefit other students.

It is argued that several techniques can be used to enrich this type of learning environment (communal knowledge), which focuses on learning with and for others. Students can carry out the activities of a course during a given year, but there is no knowledge transfer among students from one year to the next. If students were to take part in a learning process in which their knowledge could be captured, then courses would be able to promote knowledge construction rather than merely retransmit it year after year (Holmes et al., 2008).

\section{METHODOLOGY}

In order to implement intelligent tutoring in a DE course, we propose the implementation of intelligent feedback by means of a knowledge base in the formative assessment process (Figure 2). All student experiences should be stored in a database to be converted into rules so as to help students in upcoming courses.

The implementation occurred in a course in Financial Mathematics using HP12C consisting of four modules: Introduction, Simple Interest, Compound Interest, and Simple Discount. The online course is offered via Moodle and has a 40-hour workload. It has the status of a university extension course and its audience comprises 
professionals and students of finance. In order to meet the proposed objective two major steps were taken:

Step 1: creation of a knowledge base with rules based on experiences of students in previous offerings of the same course. The previous offerings of the course, which were stored in the database, were analyzed and the mistakes found were converted into rules and strategies to help future students. The rules were to comprise the correct formula, wrong formulas, error message, and links to theory or additional exercises.

Step 2: Redesign of the course using intelligent feedback as one of the formative assessment strategies. Upon receiving a student's answer, the intelligent feedback system should produce timely feedback and send a message indicating a hit or a mistake. The course was designed in accordance with online ILDF.
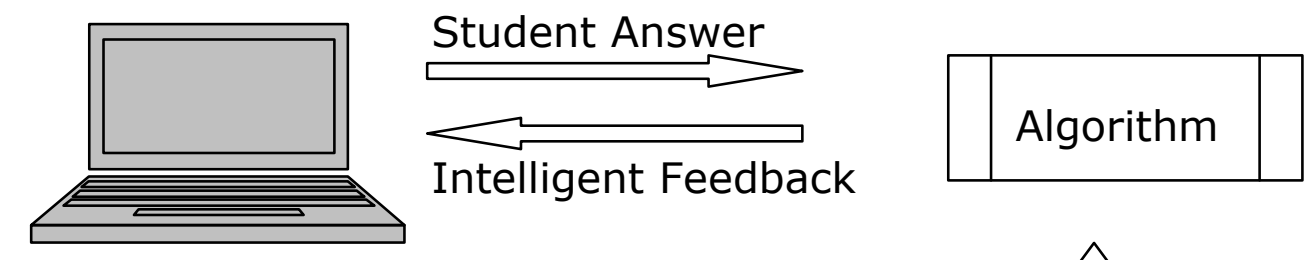

Figure 2: Intelligent Tutoring system with feedback.

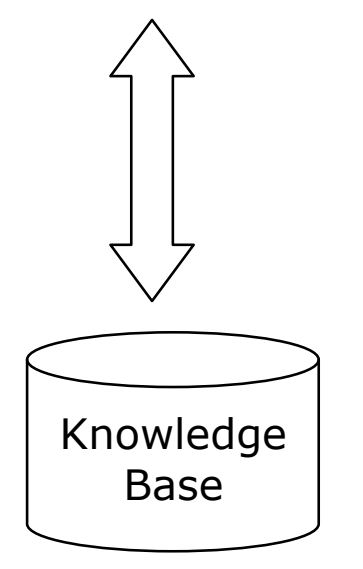

\section{RESULTS AND DISCUSSION}

The results and analysis in this study will abide by the same aforementioned steps.

Step 1 - Knowledge Base

After analyzing the data from previous offerings of the same course, it was possible to construct about 15 rules to be used in this course. Table 4 shows an example of one of the rules identified. Together with the wrong formula were individualized feedback and a link to the corresponding theory (Table 4). All the rules were incorporated into the VLE (Moodle). 


\begin{tabular}{|l|l|l|l|l|}
\hline Question & $\begin{array}{l}\text { Correct } \\
\text { Formula }\end{array}$ & $\begin{array}{l}\text { Wrong Formula } \\
\text { (Rule) }\end{array}$ & $\begin{array}{l}\text { Individualized } \\
\text { Feedback }\end{array}$ & $\begin{array}{l}\text { Link to } \\
\text { Theory }\end{array}$ \\
\hline $\begin{array}{l}\text { Determine the } \\
\text { bi-monthly } \\
\text { simple interest } \\
\text { rate }(\% \text { a.b. }) \\
\text { that makes the } \\
\text { capital } \\
\text { multiply [var1] } \\
\text { times its value } \\
\text { after [var2] } \\
\text { years. }\end{array}$ & $\begin{array}{l}((([\operatorname{var} 1]-[1]) \\
[\operatorname{var} 2]) /[6])^{*}\end{array}$ & $\begin{array}{l}((([\operatorname{var} 1]) /[\operatorname{var} 2]) / \\
[6])\end{array}$ & $\begin{array}{l}\text { As explained by the } \\
\text { theory of Simple } \\
\text { Interest, the rate is } \\
\text { estimated as a } \\
\text { percentage; } \\
\text { therefore, the value } \\
\text { should be } \\
\text { multiplied by } 100 .\end{array}$ & $\mathrm{http://..}$ \\
\hline
\end{tabular}

Table 1: Example of a rule established before the course began.

Step 2 - Redesign of the Course in Financial Mathematics using HP-12 via Intelligent Feedback

The course was redesigned according to online ILDF (Bannan-Ritland, 2003) and consisted of four modules and an end-of-course exam. Each module comprised a test with about 10 questions with variables randomly generated at each attempt. At every attempt, the system stored wrong results in its knowledge base. Conversion of mistakes into rules is presently done manually at the end of the course. The required grade in the modules for students to be able to do the end-of-course exam is 8 . Students can do the module tests as many times as necessary to obtain the desired grade, the highest grade obtained always prevailing. This favors learning in that students have to put in a lot of practice to obtain (or exceed) the required grade in the module tests.

The use of online ILDF allowed the definition of three fundamental elements of the course, which are: Educational Features, Instructional Strategies, and Instructional Tools. This means that the tools employed (e.g., forums) are justified for the implementation of the adopted strategies supported by the selected pedagogical features (based on multiple theories of learning). This means that all tools used in the course are supported by the chosen pedagogical model.

Intelligent tutoring was conducted via intelligent feedback, in which students submit answers for automatic correction. Then, the system compares the answers received with the correct answers (using the right and wrong formulas existing in the knowledge base), i.e., it applies the values of the current variables to the formula set by the teacher and compares the result with the student's answer. At this point students are redirected to another window and see a table with the following columns: (1) question number; (2) student's answer; (3) correct answer (in red if the answer is different from the student's (wrong answer) and green if the answer matches the student's (correct answer)); (4) message; and (5) a link to theory depending on whether the student's answer is right or wrong. It is important to remark that the system stores students' achievement rates in each test as well as the date when the interactions occurred in order to check later their evolution during the course.

The three following figures are examples of three types of feedback given to students. Figure 3 indicates that the student's answer is right and so he or she receives positive reinforcement in addition to supplementary material. Figure 4 illustrates the case of an unknown mistake, i.e., a mistake that is not part of the system database yet. 
In this case, the student is given some tips so as to be able to solve the problem and is directed to the theory studied in the module. It is hoped that new rules will be fed into the system every time the course is offered anew. In the third case (Figure 5), it is possible to note that the mistake has already been stored in the knowledge base. Then, the purpose of this kind of feedback is to show students a possible cause of their mistake so that they can solve the problem.

[Dear Student:We believe in your potential. Congratulations on your correct answer about Simple Interest. We believe that you can further consolidate this knowledge by doing new exercises or accessing the suggested supplementary material. Good luck and thank you!

\section{Supplementary Material \\ Simple Interest \\ Supplementary material on the topic <click here> \\ Additional exercises on the topic with answers <click here> ]}

Figure 3: Individualized feedback for a right answer.

[Dear Student: Perhaps you have not fully understood the exercise about Simple Interest (Amount). The individualized feedback system has suggested one of the possible causes for your appreciation (bear in mind that daily rates should be estimated in percentage). Based on the system answer and on the theoretical support suggested, we believe you will be able to get it right the next time you do this exercise. Good luck and thank you! Do you remember the formula? Remember to use the interest rate and period in the same unit.

\section{Theory about the exercise <click here> \\ Additional exercises about the topic with answers <click here>]}

Figure 4: Individualized feedback for an unknown wrong answer.

[Dear Student:You may not have understood the exercise about Simple Interest (Amount). The individualized feedback system has suggested one of the possible causes for your appreciation (bear in mind that daily rates should be estimated in percentage). Based on the system answer and on the theoretical support suggested, we believe you will be able to get it right the next time you do this exercise. Good luck and thank you!

\section{Theory about the exercise <click here> \\ Additional exercises about the topic with answers <click here>]}

Figure 5: Intelligent Feedback for known mistake.

In order to evaluate the potential use of Intelligent Feedback the course was piloted with just six students, which produced promising results. Table 2 shows that a student gave a wrong answer (known to the environment) and subsequently succeeded 
in getting it right. It should be remarked that the variables of an exercise are generated randomly and, as a result, are not repeated.

Based on the sample investigated, $66 \%$ of the students giving a wrong answer to the aforementioned question made use of intelligent feedback and got it right in the next interaction. Intelligent feedback is believed to have helped them to evolve cognitively.

The results from this investigation are consistent with those described by Klecker (2007), who divided his sample of students into two groups (two classes). The author demonstrated that feedback assisted students in knowledge construction, concluding that the group that had been given feedback performed better than the one that had not. This investigation is also corroborated by the study conducted by Gilman (1969), which shows the importance of giving feedback to formative assessment. In Gilman's study the students were also divided into two groups and only one group received feedback (formative assessment). The performance of the control group was significantly inferior to that of the experimental group thereby showing that formative assessment with feedback assists students in knowledge construction.

In order to check whether intelligent feedback had been helpful, some students were interviewed. These students reported that it did help them to get the right answer at least once, i.e., upon receiving feedback after making a mistake known to the system, the indication found in the answer table helped them to answer the same question correctly the next time they interacted with the questionnaire. After being asked whether the individualized feedback had helped him in some way, a student answered:

[...] the tip shown in the answer table really helped me to improve my grade in the questionnaire. There was a question that asked us to estimate the monthly rate and I did the daily rate. When I read the individualized feedback provided by the environment suggesting that I multiply the result by 30 , I returned to the question right away, did the exercise again, and I got it right this time.

Another student reported:

[...] every time I sent the answers I resorted to the individualized feedback answers to do correctly the exercises I had gotten wrong. Thus, I was able to improve my learning in many interactions.

This pilot test showed the significant potential of the proposition in this study. Not only does intelligent feedback allow teachers to assess the correctness of students' answers to problems, but it can also help the latter to improve their knowledge and promote self-directed learning.

\section{FINAL REMARKS}

Distance Education has great potential in the construction of more individualized learning in that students can be assisted on an individual basis and their individual cognitive styles can be taken into account. To this end, it is necessary that educational institutions offer top-quality courses at a distance so that students can really learn.

Regardless of the size of online classes, DE has potential to offer the necessary support for the planning and implementation of courses that successfully meet the goals 
of the teaching-learning process. It is therefore capable of assisting students on a case by case basis - by means of high-quality individualized feedback - and of helping them to build their knowledge from the accumulated experience of students from previous offerings of the same course. mentioning:

Given the aforementioned scenario, the following contributions are worth

(a) Consolidation of planning is necessary for a course to reach a significant level of quality. In this study, this planning was carried out via online ILDF, which enabled the identification of some characteristics of the different pedagogical models proposed, the selection of instructional strategies, and the implementation of these strategies in the various instructional technologies selected. In addition, Moodle was chosen as the VLE so as to facilitate the implementation of these technologies. It should be remarked that the characteristics of the teaching model as well as instructional strategies and technologies are independent from the VLE in question, enabling the migration of the created structure to any other environment that includes the resources necessary for the use of the features defined for the course;

(b) Assistance in the construction of student learning by means of feedback, in turn, played a key role in implementing the course. In this study, environmentallygenerated feedback defined the formative assessment practice. It follows then that the provision of formative assessment and feedback has great potential in that a mistake made by students can promote their learning. Thus, this study has shown that individualized feedback can assist students in building their knowledge during the course. In the case of mistakes made by students, it facilitated their evolution in order to do the exercise correctly in the next interaction with the VLE, and in the case of success, it helped them to consolidate their knowledge by means of supplementary material;

(c) Use of past experiences to assist forthcoming students in learning the subject matter (communal knowledge). As part of a cyclical process, the new rules identified during other offerings of the course (incorporated into individualized feedback) can support forthcoming students' knowledge construction. For instance, the course conducted to validate this study employed data from previous offerings of the same course. Similarly, the data generated in the current offering of the course will be used in the individualized feedback of future offerings.

In addition, one of the chief contributions of this study to DE scholarship is to indicate some aspects for further investigation, such as:

1. Identification, by means of interviews or other research methods, the reason why students make mistakes so as to prevent them, not just correct them;

2. Automation of rule generation the minute students answer the questions thereby helping other students from the same offering of the course, not just forthcoming ones. Another benefit from this procedure is to free the teacher from having to identify new rules manually and feed them into the database;

3. Automation of formative assessment by comparing data generated by students to assessment criteria defined by the tutor thereby making it possible to generate dynamic reports and graphs and for teachers to give more individualized feedback to students; 
4. Offering of a course in Financial Mathematics via HP-12 to a larger sample of students so as to consolidate the potential of individualized feedback in assisting participating students in knowledge construction.

In short, different assessment modes-especially those that comprise feedback - may be implemented in various combinations, but what really matters is that students achieve significant learning at the end of the process.

\section{REFERENCES}

Bannan-Ritland, B. (2003). The role of design in research: The integrative learning design framework. Educational Researcher, v.32, n.1, p.21-24.

Birenbaum, M.; Tatsuoka, K. K. (1987). Effects of "online" test feedback on the seriousness of subsequent errors. Journal of Educational Measurement, Summer, v.24, n.2, p.145-155.

Kulhavy, R. W. (1977). Feedback in written instruction. Review of Educational Research, v.47, n.2, p.211-232.

Bloom, B. S; Hastings, J.T.; Madaus, G.F. (1971) Manual de avaliação formativa e somativa do aprendizado escolar. São Paulo: Biblioteca Pioneira de Ciências Sociais.

Dib, C. Z. Formal, non-formal and informal education: concepts / applicability (1988). American Institute of Physics, New York, p.300-315. Disponível em: < http://www.techne-dib.com.br/downloads/6.pdf>. Acesso em: 3 Apr. 2008.

Ferreira, M. C.; Carvalho, L.M.O.(2004) A Evolução de jogos de Física, a avaliação formativa e a prática reflexiva do professor. Revista Brasileira de Ensino de Física, São Paulo, v.26, n.1, p.57-61.

Gilman, D. A.(1969) Comparison of several feedback methods for correcting errors by computer-assisted instruction. Journal of Educational Psychology, Washington, v.60, n.6, p.503-08.

Holmes, B.; Gardner, J. E (2006) learning theory - communal constructivism. In: ELEARNING: concepts and practice. Londres: Sage, p. 76-89.

Holmes, B., Tangney, B., Fitzgibbon, A., SAVAGE, T., MEHAN, S. (2008) Communal constructivism: students constructing learning for as well as with others. In: SOCIETY FOR INFORMATION TECHNOLOGY AND TEACHER EDUCATION INTERNATIONAL CONFERENCE, DUBLIM. PROCEEDINGS. Disponível em: <https://www.cs.tcd.ie/publications/tech-reports/reports.01/TCD-CS-2001-04.pdf> Acesso em: 25 jan. 2009.

Klecker, B. M.(2007) The impact of formative feedback on student learning in an online classroom. Journal of Instructional Psychology, Washington, v.34, n.3, p.161165.

Maximo, L. F., Raabe, A. L. A., Barone, D. A. C.(2007) Avaliação formativa assistida por computador no ensino a distância. Novas Tecnologias na Educação, Porto Alegre, Brasil, v.5, n.1, p.1-16. 
Oliveira, J. P. M. (1999) Sistemas Inteligentes de Ensino na Internet. Cadernos de Informática. Porto Alegre, v.2, n.1.

Oliveira Neto, J. D. , CORNACHIONE JUNIOR, E., NASCIMENTO, E. (2009). Paving the path for those who come after: designing online instruction to make the best use of previous student's experiences in light of communal knowledge. In: PROCEEDINGS....,2009, Anais... Washington D. C. Academy of Human Resource Development.

Otsuka, J. L., Lachi, R. L., Ferreira, T. B., ROCHA, H. V. (2002) Suporte à avaliação formativa no ambiente de educação a distância Teleduc. In: VI CONGRESSO IBEROAMERICANO DE INFORMÁTICA EDUCATIVA, 6., Vigo. Anais... Campinas: Universidade Estadual de Campinas, 2002. p. 1-12

Perrenoud, P. (1999) Avaliação: da excelência à regulação das aprendizagens entre duas lógicas. Porto Alegre: Artes Médicas.

Piletti, C.(1987) Didática geral. São Paulo: Ática.

Pisan, Y. et al. (2002). Providing timely feedback to large classes. In: PROCEEDINGS..., 2.,2002, IEEE. p. 1-2

Rosa, M.; maltempi, M.V. A (2006)Avaliação vista sob o aspecto da educação a distância. Ensaio: avaliação e políticas públicas em educação, Rio de Janeiro, v.14, n. 50, p. 57-76.

Souza, P. C. (2003) Diretrizes para a construção de mediadores sócio-construtivistas em sistemas de aprendizagem colaborativa apoiada por computador. 2003. 155f. Tese (Doutorado) - Programa de Pós-graduação em Engenharia de Produção, Universidade Federal de Santa Catarina.

Vasconcellos, M. M. M. et al. (2006). O professor e a boa prática avaliativa no ensino superior na perspectiva de estudantes. Interface - Comunicação, Saúde, Educação, v.10, n.20, p.443-456. 
122 Oliveira Neto, J. D. de., Nascimento, E. V. 